\title{
APORIAS DA MEMÓRIA: ESTRATÉGIAS DE ESCRITA RESISTENTE EM TRÊS ROMANCES CONTEMPORÂNEOS BRASILEIROS
}

\author{
Dayane de Oliveira Gonçalves ${ }^{1}$
}

Resumo: A partir da dupla possibilidade de constituição de narrativas de resistência, apresentada por Alfredo Bosi (1996), coloca-se em foco os romances K. Relato de uma busca (2011), de Bernardo Kucinski; Não falei (2014), de Beatriz Bracher; e O corpo interminável (2019), de Claudia Lage. Os três romances, ao abordarem a ditadura civil-militar brasileira, bem como suas consequências que ainda se fazem presentes, muito em razão de um processo de reconciliação extorquida, apresentam certamente uma temática de resistência. Pretende-se, no entanto, pensá-los também a partir da concepção de resistência como forma imanente à escrita. Para tanto, objetiva-se verificar as estratégias narrativas utilizadas, buscando conferir a hipótese de que a aporia da memória guarda em si a faísca da potência estética de cada romance, das saídas formais que cada um deles irá encontrar para lidar, então, com as (im)possibilidades da narração da memória.

Palavras-chave: romance brasileiro contemporâneo; ditadura civil-militar brasileira; memória; resistência.

Abstract: Based on the twofold resistance narratives possibility, presented by Alfredo Bosi (1996), the focus is on the novels K. Relato de uma busca (2011), by Bernardo Kucinski; Não falei (2014), by Beatriz Bracher; and O corpo interminável (2019), by Claudia Lage. The three novels, when approaching the Brazilian civil-military dictatorship, as well as its consequences that are still present, due to a process of extorted reconciliation, undoubtedly have a theme of resistance. However, it is intended to think about them also from the conception of resistance as an immanent form to writing. For this purpose, the objective is to verify the narrative strategies used, looking to check the hypothesis that the aporia of the memory holds within itself the spark of the aesthetic potency of each novel, of the formal resolutions that each of them will find to deal with the (im)possibilities of memory narration.

Keywords: contemporary Brazilian novel; Brazilian civil-military dictatorship; memory; resistance.

1 Doutoranda no Programa de Pós-Graduação em Letras: Estudos Literários da Universidade Federal de Minas Gerais (Pós-Lit/UFMG).E-mail: doliveirag@outlook.com 


\section{Introdução}

Alfredo Bosi, em "Narrativa e resistência", define resistência como uma força, interior ao sujeito, que resiste a outra força, exterior: "Resistir é opor a força própria à força alheia. O cognato próximo é in/sistir; o antônimo familiar é de/sistir" (BOSI, 1996, p. 11). Ademais, afirma Bosi que, a princípio, tal conceito é originalmente ético e não estético. Assim sendo, considerando-se o modelo idealista de Benedito Croce na dialética das distinções, poderia haver uma certa contradição em se considerar, por exemplo, a concepção de narrativa de resistência, em que estariam conjugados conceitos próprios da ética/política e da estética/ arte. No entanto, essa contradição (somente aparente), na realidade concreta (em oposição ao nível abstrato e idealista), torna-se justamente, conforme Bosi, a garantia da vitalidade das esferas artísticas e teóricas: "no fazer-se concreto e multiplamente determinado da existência pessoal, fios subterrâneos poderosos amarram as pulsões e os signos, os desejos e as imagens, os projetos políticos e as teorias, as ações e os conceitos" (BOSI, 1996, p. 13). Explorando, então, a noção de narrativa de resistência, o autor afirma que esta pode se realizar de duas maneiras, as quais não necessariamente se excluem: a resistência como tema e a resistência como processo constitutivo de uma certa escrita.

Enquanto tema, a resistência aparece de forma mais explícita no texto, quando neste há representação na qual se evidencia posicionamento contrário aos antivalores operantes em um determinado meio; isso explicaria a razão de a "resistência como tema" ser um tópos presente em momentos de aceleração de luta social. Assim, não restam dúvidas de que a literatura brasileira que tematizou e continua tematizando, nos dias atuais, os anos e/ou as consequências ainda presentes da ditadura civil-militar instaurada a partir de 1964 é uma literatura resistente, a qual resiste, sobremaneira, a um projeto político que induz ao esquecimento alienante do horror, que, por sua vez, abre espaços na sociedade ao negacionismo e à possibilidade consequente de repetição de um golpe militar.

Os três romances considerados neste artigo, todos da segunda década do século XXI K. Relato de uma busca (2011), de Bernardo Kucinski; Não falei (2014), de Beatriz Bracher; e O corpo interminável (2019), de Claudia Lage - são, evidentemente, narrativas de resistência em seu caráter temático. Eles incorporam como tema o não expurgamento dos traumas da ditadura, que permanecem como "não-resolvidos", mesmo meio século depois, seja para a sociedade brasileira como um todo ou para os que foram afetados por ela de um modo mais direto - consequências, em grande medida, resultantes de como se deu a Lei da Anistia (1979) e, em geral, o processo de transição democrática no Brasil.

Jeanne Marie Gagnebin, em “O preço de uma reconciliação extorquida”, adverte sobre as políticas de anistia que a utilidade delas é de, no máximo, tornar possível "uma sobrevivência imediata do conjunto da nação enquanto tal, mas não garantem uma coexistência em comum duradoura" (GAGNEBIN, 2010, p. 179); assim, a política de anistia "não pode pretender ser uma política definitiva de regulamento da memória histórica" (GAGNEBIN, 2010, p. 180), porque ela não é solução, reconciliação, menos ainda perdão. Contrariamente a tudo isso ergueu-se a Lei da Anistia brasileira, "ampla e irrestrita", que propôs o silêncio e a imposição forçada do esquecimento, como se fosse possível sob ela enterrar definitivamente 21 anos de trágica história nacional. Esse projeto reconciliatório é, no entanto, insus- 
tentável, "porque a memória efetiva não se deixa controlar, somente se deixa calar - às vezes também manipular, mas volta” (GAGNEBIN, 2010, p. 183).

Sendo assim, a respeito da representação do retorno desses denegados pelos romances selecionados, propõe-se, neste artigo, pensá-los a partir da ideia de resistência também como forma imanente da escrita, apresentada como segunda possibilidade por Bosi; ou seja, a partir de uma tensão interna (e formal) que torna tais escritas resistentes para além do tema.

\section{A escrita resistente em $K .$, Não falei e O corpo interminável}

Para tratar da resistência como forma imanente da escrita, Bosi recorre ao conceito de tensão, o qual, de acordo com o autor, subjaz à própria ideia de resistência:

Chega um momento em que a tensão eu/mundo se exprime mediante uma perspectiva crítica, imanente à escrita, o que torna o romance não mais uma variante literária da rotina social, mas o seu avesso; logo, o oposto do discurso ideológico do homem médio. O romancista "imitaria" a vida, sim, mas qual vida? Aquela cujo sentido dramático escapa a homens e mulheres entorpecidos ou automatizados por seus hábitos cotidianos. A vida como objeto de busca e construção, e não a vida como encadeamento de tempos vazios e inertes. Caso essa pobre vida-morte deva ser tematizada, ela aparecerá como tal, degradada, sem a aura positiva com que as palavras "realismo" e "realidade" são usadas nos discursos que fazem a apologia conformista da "vida como ela é"... A escrita de resistência, a narrativa atravessada pela tensão crítica, mostra, sem retórica nem alarde ideológico, que essa "vida como ela é" é quase sempre, o ramerrão de um mecanismo alienante [...]" (BOSI, 1996, p. 23, grifos do autor).

Dessa forma, a tensão é destacada como um dos constituintes de uma escrita resistente e uma das suas formas de expressão, conforme chama atenção o autor, dá-se por meio de uma perspectiva crítica e imanente à escrita que estabelece uma tensão com parâmetros e convenções de "realismo" e "realidade", os quais estariam ligados a uma pretensão de narrar a "vida como ela é". A perspectiva crítica torna-se, portanto, uma das chaves principais dessa tensão pressuposta na escrita resistente, à medida que a resistência apareceria como:

um movimento interno ao foco narrativo, uma luz que ilumina o nó inextricável que ata o sujeito ao seu contexto existencial e histórico. Momento negativo de um processo dialético no qual o sujeito, em vez de reproduzir mecanicamente o esquema das interações onde se insere, dá um salto para uma posição de distância e, deste ângulo, se vê a si mesmo e reconhece e põe em crise os laços apertados que o prendem à teia das instituições (BOSI, 1996, p. 26).

Pode-se afirmar, assim, que os três romances escolhidos para o recorte deste artigo, além da temática de resistência, empreendem escritas resistentes, cujas narrativas, entran- 
çando os fios da memória com os da imaginação, constituem perspectivas críticas e em tensão com as limitações do que providenciou a realidade: restos lacunares de uma história. Com estratégias formais distintas, em cada caso, os romances incorporam a ausência como matéria, criando e dizendo, como podem, um vazio de memória - o que não pode mais esperar por um esclarecimento que chegue pelo discurso histórico, que dependeria da revisão da Lei da Anistia, da abertura de documentos ainda suprimidos (se não completamente destruídos) pelo exército, pela institucionalização e patrimonialização de lugares de memória entre outros.

Em K. Relato de uma busca, a saga de um pai (K.) à procura da filha desaparecida pelos militares na década de 1970 é transmitida por um narrador cuja escolha merece atenção. Trata-se de um narrador onisciente intruso que, por vezes, tece comentários lançando mão da sua onisciência, como quando, ao contar as desventuras de K. para derrubar "o muro de silêncio em torno do sumidouro de pessoas, o que nem gente muito importante havia conseguido", pondera que "ele não podia saber que quarenta anos depois esse muro ainda estará de pé, intocado" (KUCINSKI, 2014, p. 145-146). Assim é que, nesse romance, duas temporalidades são articuladas numa relação em que passado e presente vão se desvelando mutuamente.

Além da jornada de K., a qual podemos chamar narrativa principal, gravita em torno dela muitos outros quadros narrativos, nos quais variam as vozes e perspectivas. Nessas narrativas, episódios do que poderia ter acontecido são reconstruídos ficcionalmente, cumprindo uma função suplementar e se apresentando onde no discurso histórico há o vazio. Esses quadros ora recriam a existência e a voz dos que não podem testemunhar porque sucumbiram para sempre, ora daqueles a quem a imposição do esquecimento forçado beneficiou, de modo que permanecem ainda hoje calados, como militares e torturadores. Um exemplo é o capítulo intitulado "A abertura", cujo foco narrativo é alterado para uma narração em $1^{a}$ pessoa, no qual se ficcionaliza a voz de um delegado do Departamento de Ordem e Política Social (DOPS), Fleury: "É do consulado? Me chamem o Rocha, por favor, digam que é o Fleury.” (KUCINSKI, 2015, p. 71). Essas alternâncias dão a ver o lado oposto da saga de K., o lado das forças que operam contra os resultados de suas buscas por informações sobre a filha. Ademais, é interessante notar como essa voz ficcionalizada tematiza o próprio processo de apagamento dos rastros, cujas consequências são as lacunas de uma memória histórica que o texto ficcional tenta, à sua maneira, reconstituir:

Mineirinho, senta aí. Tá acontecendo uma coisa estranha. Não estou gostando nada. Sabe quem me procurou? O cara da cia, Mineirinho, o Robert, nem mais nem menos. [...] O Robert diz que mudou tudo. Que agora é a hora de limpar os arquivos, não deixar prova. Como se eu não soubesse. Entregar a moça, onde é que o cara tem a cabeça? Mesmo que eles estivessem vivos, como é que ia entregar, depois de tudo o que aconteceu? Não é para acabar com as provas? Pois nós acabamos. Muito antes deles mandarem. Fala a verdade, Mineirinho, perto de mim esses gringos não são nada, tudo amador. (KUCINSKI, 2015, p. 75-6)

Nos outros dois romances também se percebe um mecanismo formal em que a estrutura se compõe por uma narrativa principal - narrada sob a voz de Gustavo, em Não falei, e | 86 | 
de Daniel, em O corpo interminável - rodeada por outros diversos tipos de fragmentos, que descentram o foco narrativo limitado de primeira pessoa das narrativas principais, evidenciando a inviabilidade da composição homogênea de um passado rasurado e fraturado pelo impacto do trauma.

Gustavo foi torturado - ficou um pouco surdo, perdeu alguns dentes, teve quebrado alguns ossos da mão -, mas, principalmente, não delatou Armando, seu amigo e cunhado, embora pareça ter sido essa a conclusão a que chegou seu círculo mais próximo. O título da obra é uma referência à negação da delação e também à impossibilidade assumida de responder a ela publicamente, de negá-la. Como uma espécie de leitmotiv, o parágrafo que abre o romance ecoa em outros momentos do texto:

Se fosse possível um pensamento sem palavras ou imagens, inteiro sem tempo ou espaço, mas por mim criado, uma revelação do que em mim se esconde e pronto está, se fosse possível que nascesse assim evidente e sem origem aos olhos de todos e então, sem o esforço do meu sopro - tom de voz, ritmo e hesitação, meus olhos - surgisse como pensamento de cada um, ou ainda, uma coisa, mais que um pensamento, se coisa assim fosse possível existir, eu gostaria de contar uma história (BRACHER, 2014, p. 7).

Essa preocupação é dominante em Gustavo durante seu fluxo rememorativo que remonta aos eventos das últimas três décadas, o qual é aquecido e colocado em marcha, uma vez que ele se prepara, recém aposentado, para mudar de cidade e para a entrega da casa familiar que fora vendida (por isso, em contato com papéis e outros rastros do passado encontrados pela casa) e, ao mesmo tempo, em razão da possibilidade considerada, a qual ele tenta ensaiar, de conceder entrevista à Cecília, uma jovem romancista interessada em sua história e que é a ele apresentada por uma amiga de trabalho na universidade.

O romance, no entanto, termina com a seguinte frase, recuada do restante corpo do texto: "Eu falaria isso, Cecília, se fosse possível." (BRACHER, 2014, p. 148). Tal fim deixa em aberto muitas possibilidades interpretativas. Entre elas, uma que remete novamente ao título, dando a ele mais uma camada de sentido: o da impossibilidade de narrar a sua história à Cecília, um passado que, de tal modo fraturado pelo trauma, não se põe de pé com inteireza e que só poderia ser traduzido se o impossível fosse possível (a transmissão ideal contida na ideia leitmotiv).

O trauma que marca e fragmenta Gustavo, além da tortura sofrida e da injusta acusação, é o da ausência do amigo a qual se juntam - em um "efeito borboleta" - a morte de sua esposa no exílio e o suicídio da sogra, por não suportar a fatalidade que acomete os dois filhos. O narrador afirma em determinado momento que poderia ter lidado com a situação se o morto tivesse sido outro: "eu poderia sentar-me e discutir o assunto, [...] tentar mostrar ao amigo meus olhos, lembrá-lo de quem eu sou, fazê-lo ver [...] enxergar e arrancar-lhe a dúvida com o toque da minha mão, escuta, sou eu que estou aqui, o mesmo" (BRACHER, 2014, p. 70). No entanto, tendo sido Armando, era impossível, porque "qualquer esforço em negar a traição implicaria que ela poderia ter acontecido e isso era incompreensível para mim, um ferro em brasa marcando as ancas do boi [...]" (BRACHER, 2014, p. 70). As causas que poderiam explicar a captura de Armando, que não a sua delação, são buscadas pelo narrador: 
Armando fora entregue por minha causa, não por minha boca, mas isso não fazia diferença. Minha prisão deve tê-lo forçado a se expor, [...] E provavelmente fui preso por sua causa. E nessas causas todas esquecíamos a causa visível e incontestável, os homens que foram à minha casa e me prenderam, os homens que foram ao seu refúgio e o mataram. Militares, agentes da repressão, Operação Bandeirantes, os porões dos poderes [...] (BRACHER, 2014, p. 117).

Dessa forma é que Gustavo, marcado em brasa pelo estigma de traidor, torna-se o eleito desgraçado no bem-sucedido processo de transferência da culpa do Estado para o indivíduo, outra das facetas de um passado sobre o qual o esclarecimento vem sendo negado.

Por sua vez, O corpo interminável é o único entre os três romances em que se figura um narrador escritor, cuja narração dá conta do próprio ato narrativo de escrita, num gesto metaficcional explícito: a narrativa abarca muitos momentos de consciência de escrita e comentários sobre as suas próprias dificuldades e limites éticos.

Assim como em $K$., o enredo da narrativa principal é definido por uma busca, por um luto negado na impossibilidade do corpo da mãe desaparecida. No entanto, a busca de Daniel - filho dessa militante da qual ele não tem nenhuma memória - é muito mais por respostas de um sujeito que deseja conhecer a sua história e, indissociáveis que são, a de sua mãe, esta narrativa que lhe é negada pelo avô, o qual apaga todos os rastros e vestígios da filha, à exceção de uma única foto que entrega ao neto e que dá a este a saber o rosto da mãe desaparecida.

Contra essa tentativa de apagamento da existência da filha pelo pai (cujas justificativas vão se desvelando aos poucos na narrativa), o surgimento do neto significa a sobrevivência do mais significativo "resto". O avô lhe diz: "Eu tinha certeza, mas um dia um rapaz apareceu com um bebê nos braços, eu tinha certeza, garoto, não tinha restado nada, restou você." (LAGE, 2019, p. 89).

Assim, o título faz referência ao corpo desaparecido da mãe, interminável porque sua presença fantasmagórica no presente não pode ser encerrada no trabalho de luto, inviabilizado pela ausência do corpo. Mas, pode-se pensar também na referência a um corpo cuja ausência de limites (por isso interminável) cria um amálgama que é, na sequência, violentamente partido - Daniel é o resto de carne que sobrou do corpo de Júlia. Seu próprio corpo é parte que se estendeu do corpo desaparecido da mãe. A cena em que Daniel escreve (e, para tanto, precisa imaginar) os sofrimentos de tortura a partir de uma perspectiva de dentro do útero da mãe corrobora essa ideia:

[...] Sofro por ela que enlaça a barriga, tateia a circunferência à minha procura, quer adivinhar onde estou, mas ela deve saber que ainda é cedo, embora esteja em seu útero não estou em lugar nenhum, sou uma presença anterior à forma, não posso me reunir nem me dispersar, por isso, talvez, por essa situação ainda indefinida, estamos tão entranhados que sinto todos os estremecimentos que ela sente, os choques que queimam a sua pele me queimam também, as pancadas ferem a nós dois num único golpe, quase escrevo, o corpo da minha mãe também é o meu, escrevo, é com esse corpo que inicio a vida, é nesse corpo que conheço a brutalidade [...] (LAGE, 2019, p. 153). 
O enfrentamento a que Daniel se propõe ao escrever a sua história e, precariamente, a da mãe só é possível a partir do exercício literário; "por assim dizer, só com a arte a intraduzibilidade pode ser desafiada - mas nunca totalmente submetida" (SELIGMANN-SILVA, 2003 , p. 47). As narrativas que se alternam com a principal compreendem muitas vozes que, como em $K$., abrem um espaço de circulação de vozes impedidas. Gravita, assim, em torno da narrativa principal, uma série de histórias interrompidas, fragmentadas, sem fechamento, mas, de alguma forma, entrelaçadas. Alguns desses fragmentos compreendem a voz de uma mulher, militante, grávida, sugerindo uma reconstituição da voz da mãe; em outros, uma mulher em condições semelhantes aparece vista por um narrador observador. Esses fragmentos não constituem uma história com continuidade - ora essa mulher dá à luz antes de ser capturada pelos militares, ora o bebê nasce nos porões, entre outras. Assim, essas narrativas constituem um mosaico de possibilidades de uma mulher que, não podendo ter sua história bem delimitada (de onde também se pode extrair uma acepção do corpo interminável), são várias e, provavelmente, ao mesmo tempo, nenhuma dessas cujas histórias são narradas. Isso, no entanto, não anula o gesto restitutivo, "um ato obrigatório e não secundário para a fundação de uma memória comunitária também dos anos obscenos e mudos, pelo menos do ponto de vista das vítimas, do horror" (VECCHI, 2015, p. 155), uma vez que, na esteira do argumento de Ettore Finazzi Agrò (2014), o processo de ficcionalização por qual passa a representação do passado pela literatura não tira desta a sua potência em posicionar os problemas do real.

Enfim, o mal-estar quanto à operação de apagamento forçado é elaborado e nomeado - totalitarismo institucional - em um dos momentos de reflexão do narrador de K.:

[...] Enterrar os casos sem enterrar os mortos, sem abrir espaço para uma investigação. Manobra sutil que tenta fazer de cada família cúmplice involuntária de uma determinada forma de lidar com a história. O "totalitarismo institucional" exige que a culpa, alimentada pela dúvida e opacidade dos segredos, e reforçada pelo recebimento das indenizações, permaneça dentro de cada sobrevivente como drama pessoal e familiar e não como a tragédia coletiva que foi e continua sendo, meio século depois (KUCINSKI, 2014, p. 169).

Tal fragmento mobiliza em poucas linhas aspectos que podem ser encarados como chaves de leitura para os três romances. O presente, essa temporalidade em que se paga o preço da reconciliação extorquida, está dado a ver nas dobras desses romances, na individualização do trauma da ditadura, no peso psicológico da herança mnemônica do sobrevivente e/ou no seu dever de memória, no funcionamento dos mecanismos de transferência da culpa do Estado para o indivíduo, nos abusos da memória e do esquecimento, de tal modo que esses romances não somente se voltam ao passado fechado em si mesmo, mas, também, e principalmente, à presença sufocadora do passado mal resolvido no presente. 


\section{Considerações finais}

Se a Guerrilha do Araguaia é o silêncio e o vazio paradigmático da ditadura brasileira, por outro lado, as consequências do passado parcialmente suprimido e da verdade encoberta nessas outras violências de Estado trazidas à cena pelos romances selecionados - o corpo desaparecido da filha, o corpo desaparecido da mãe, a vítima transformada em culpada - não podem também dispensar ainda o aparato literário formal e ficcional no processo esclarecedor, de revelação e de resistência de memória. É nesse sentido, portanto, que tais narrativas, a partir da representação de um real que só é possível por meio da ficcionalização, de construções de linguagem empreendidas e elaboradas esteticamente, para além da resistência como tema, tornam-se também escritas que guardam uma resistência imanente. Sob o signo da simultânea necessidade e impossibilidade de restituição do passado, a aporia da memória guarda em si a faísca da potência estética de cada romance, das saídas formais que cada um deles irá encontrar para lidar, então, com essas (im)possibilidades.

Pode-se dizer, assim, que elas se filiam em um projeto literário que emerge sob uma demanda de esclarecimento e que parte do pressuposto de que, conforme Roberto Vecchi, o limite da teoria é sempre um limiar para o literário e, nesse movimento, ambos criam uma solidariedade profunda, talvez a única possível "entre uma factualidade fraturada e unitariamente impossível e uma ficcionalidade como campo de reorganização e interrogação dos rastos sobreviventes e escassos de uma violência destruidora total e definitiva" (VECCHI, 2015, p. 151). Ou, ainda, pode-se dizer, com as palavras de Bosi: "o espaço da literatura, considerado em geral como o lugar da fantasia, pode ser o lugar da verdade mais exigente." (BOSI, 1996, p. 27).

\section{Referências Bibliográficas}

BOSI, Alfredo. Narrativa e resistência. Itinerários - Revista de Literatura. Araraquara, n. 10, 1996, p. 11-27.

BRACHER, Beatriz. Não falei. São Paulo: Editora 34, 2014.

FINAZZI-AGRÒ, Ettore. (Des)memória e catástrofe: considerações sobre a literatura pós-golpe de 1964. Estud. Lit. Bras. Contemp. 2014, n. 43, pp. 179-190.

GAGNEBIN, Jeanne Marie. O preço de uma reconciliação extorquida. In: Teles, E.; Safatle, V. (Orgs.). O que resta da ditadura: a exceção brasileira. São Paulo: Boitempo, 2010.

KUCINSKI, Bernardo. K. - Relato de uma busca (2011). São Paulo: Cosac Naif, 2014.

LAGE, Claudia. O corpo interminável. Rio de Janeiro: Record, 2019.

SELIGMANN-SILVA, Marcio. Apresentação da questão: a literatura do trauma. In: Seligmann-Silva, M. (Org.). História, memória, literatura: o testemunho na Era das Catástrofes. Campinas: Editora de 
Unicamp, 2003.

VECCHI, Roberto. Desaparição política e ditadura militar no Brasil: a literatura como ato de restituição. In: Vasquez, R. B. et al. Estudos da AIL em literatura, história e cultura brasileiras. Santiago de Compostela; Coimbra: Associação Internacional de Lusitanistas, 2015. 
